\title{
Bargaining over Babies: Theory, Evidence, and Policy Implications

\author{
Online Appendix
}

\section{Matthias Doepke and Fabian Kindermann}

\section{A Proofs for Propositions in Main Text}

Proof of Proposition 1: The bargaining problem can be solved via backward induction, i.e., we first solve for the ex-post allocation for a given fertility choice, and then consider the optimal fertility choice in the first stage.

If the couple decides not to have a child $(b=0)$, then resource allocation is determined by the maximization problem:

$$
\max _{c_{f}, c_{m}}\left[c_{f}-w_{f}\right]^{0.5}\left[c_{m}-w_{m}\right]^{0.5} \quad \text { s.t. } \quad c_{f}+c_{m}=(1+\alpha)\left[w_{f}+w_{m}\right]
$$

Here $\alpha$ is an efficiency scale factor that defines the surplus of a joint household. Individual consumption in this case is given by:

$$
c_{f}(0)=w_{f}+\frac{\alpha}{2}\left[w_{f}+w_{m}\right] \quad \text { and } \quad c_{m}(0)=w_{m}+\frac{\alpha}{2}\left[w_{f}+w_{m}\right]
$$

and utilities are:

$$
u_{f}(0)=w_{f}+\frac{\alpha}{2}\left[w_{f}+w_{m}\right] \quad \text { and } \quad u_{m}(0)=w_{m}+\frac{\alpha}{2}\left[w_{f}+w_{m}\right]
$$

If the partners do decide to have a child $(b=1)$, the resource allocation solves the maximization problem:

$$
\max _{c_{f}, c_{m}}\left[c_{f}+v_{f}-w_{f}\right]^{0.5}\left[c_{m}+v_{m}-w_{m}\right]^{0.5} \quad \text { s.t. } \quad c_{f}+c_{m}=(1+\alpha)\left[w_{f}+w_{m}-\phi\right]
$$

The first-order conditions give:

$$
c_{f}+v_{f}-w_{f}=c_{m}+v_{m}-w_{m},
$$


and plugging this into the budget constraint yields:

$$
\begin{gathered}
c_{f}(1)=w_{f}-v_{f}+\frac{\alpha}{2}\left[w_{f}+w_{m}-\phi\right]+\frac{1}{2}\left[v_{m}+v_{f}-\phi\right] \\
c_{m}(1)=w_{m}-v_{m}+\frac{\alpha}{2}\left[w_{f}+w_{m}-\phi\right]+\frac{1}{2}\left[v_{m}+v_{f}-\phi\right] .
\end{gathered}
$$

Utilities are then:

$$
\begin{gathered}
u_{f}(1)=w_{f}+\frac{\alpha}{2}\left[w_{f}+w_{m}-\phi\right]+\frac{1}{2}\left[v_{m}+v_{f}-\phi\right], \\
u_{m}(1)=w_{m}+\frac{\alpha}{2}\left[w_{f}+w_{m}-\phi\right]+\frac{1}{2}\left[v_{m}+v_{f}-\phi\right] .
\end{gathered}
$$

Consequently, the partners equally share the monetary surplus from cooperation as well as the surplus from having children. Given the utilities for a given fertility choice, we can now consider whether the couple will choose to have a child. The female partner prefers to have a child if:

$$
u_{f}(1) \geq u_{f}(0) \quad \Leftrightarrow \quad v_{f}+v_{m} \geq \phi(1+\alpha)
$$

The same condition applies to the male partner. Consequently, there is no disagreement, i.e. either both partners want to have a child, or both prefer to remain childless.

Proof of Proposition 2: We once again characterize the outcome by backward induction. In the case without children, the resource allocation of the couple solves the maximization problem:

$$
\max _{c_{f}, c_{m}}\left[c_{f}-w_{f}\right]^{0.5}\left[c_{m}-w_{m}\right]^{0.5} \quad \text { s.t. } \quad c_{f}+c_{m}=(1+\alpha)\left[w_{f}+w_{m}\right]
$$

which is the same as under the commitment case. Consequently,

$$
c_{f}(0)=w_{f}+\frac{\alpha}{2}\left[w_{f}+w_{m}\right] \quad \text { and } \quad c_{m}(0)=w_{m}+\frac{\alpha}{2}\left[w_{f}+w_{m}\right]
$$

and utilities are:

$$
u_{f}(0)=w_{f}+\frac{\alpha}{2}\left[w_{f}+w_{m}\right] \quad \text { and } \quad u_{m}(0)=w_{m}+\frac{\alpha}{2}\left[w_{f}+w_{m}\right]
$$

In the case with children, the maximization problem to determine the resource allocation is now different, because bargaining takes place ex post, with the new outside options given the presence of a child:

$$
\max _{c_{f}, c_{m}}\left[c_{f}-\left(w_{f}-\chi_{f} \phi\right)\right]^{0.5}\left[c_{m}-\left(w_{m}-\chi_{m} \phi\right)\right]^{0.5} \quad \text { s.t. } \quad c_{f}+c_{m}=(1+\alpha)\left[w_{f}+w_{m}-\phi\right] .
$$


First-order conditions now give us:

$$
c_{f}-\left(w_{f}-\chi_{f} \phi\right)=c_{m}-\left(w_{m}-\chi_{m} \phi\right)
$$

and plugging this into the budget constraint yields:

$$
\begin{gathered}
c_{f}(1)=w_{f}-v_{f}+\frac{\alpha}{2}\left[w_{f}+w_{m}-\phi\right]+\left[v_{f}-\chi_{f} \phi\right], \\
c_{m}(1)=w_{m}-v_{m}+\frac{\alpha}{2}\left[w_{f}+w_{m}-\phi\right]+\left[v_{m}-\chi_{m} \phi\right] .
\end{gathered}
$$

Utilities then are:

$$
\begin{aligned}
& u_{f}(1)=w_{f}+\frac{\alpha}{2}\left[w_{f}+w_{m}-\phi\right]+\left[v_{f}-\chi_{f} \phi\right] \text { and } \\
& u_{m}(1)=w_{m}+\frac{\alpha}{2}\left[w_{f}+w_{m}-\phi\right]+\left[v_{m}-\chi_{m} \phi\right] .
\end{aligned}
$$

Couples again share the monetary surplus from cooperation, but now the utility surplus from fertility is purely private. We can now move to the first stage and characterize the fertility preferences of the two partners. The woman wants to have a child if:

$$
u_{f}(1) \geq u_{f}(0) \quad \Leftrightarrow \quad v_{f} \geq\left(\chi_{f}+\frac{\alpha}{2}\right) \phi
$$

and the male partner would like to have a child if:

$$
u_{m}(1) \geq u_{m}(0) \quad \Leftrightarrow \quad v_{m} \geq\left(\chi_{m}+\frac{\alpha}{2}\right) \phi
$$

In these inequalities, the term $\chi_{g} \phi$ represents the direct cost of having the child to partner $g$. Since bargaining is ex post, having a child lowers the outside option, so that (unlike in the commitment solution) the partner bearing the greater child care burden is not compensated. The second term $(\alpha / 2) \phi$ represents the loss in marital surplus due to the cost of a child. This part of the cost of childbearing is shared equally between the partners.

Depending on $v_{f}$ and $v_{m}$, it is possible that neither, both, or just one of the partners would like to have a child. Hence, in the case of lack of commitment disagreement between the two partners about fertility is possible.

\section{B The Distribution of the Burden of Child Care and the Fertility Rate}

In this section, we examine how in an economy with many couples who are heterogeneous in child preferences the average fertility rate depends on the distribution of the child care burden. Consider an economy with a continuum of couples. The cost shares $\chi_{f}$ and $\chi_{m}=1-\chi_{f}$ are 
identical across couples. In contrast, child preferences are heterogeneous in the population, with a joint cumulative distribution function of $F\left(v_{f}, v_{m}\right)$. For a child to be born, both (7) and (8) have to be satisfied. For ease of notation, we denote the threshold values for the woman's and man's child preference above which they would like to have a child by $\tilde{v}_{f}$ and $\tilde{v}_{m}$ :

$$
\begin{aligned}
\tilde{v}_{f} & =\left(\chi_{f}+\alpha / 2\right) \phi \\
\tilde{v}_{m} & =\left(\chi_{m}+\alpha / 2\right) \phi=\left(1-\chi_{f}+\alpha / 2\right) \phi .
\end{aligned}
$$

The expected number of children $E(b)$ (i.e., the fraction of couples who decide to have a child) is given by:

$$
E(b)=1-F\left(\tilde{v}_{f}, \infty\right)-F\left(\infty, \tilde{v}_{m}\right)+F\left(\tilde{v}_{f}, \tilde{v}_{m}\right) .
$$

That is, the couples who don't have a child are those where either the woman's or the man's fertility preference is below the threshold; the last term is to prevent double-counting couples where both partners are opposed to having a child.

We interpret the cost parameters $\chi_{f}$ and $\chi_{m}$ as driven partly by government policy, and partly by social norms. For example, there may be a social norm that women do most of the work in raising children, especially in the case of non-cooperation between the couples (which is where the distribution of the burden matters). The extent to which this norm will affect bargaining will depend also on the availability of public child care. If public child care is available, the man will be more likely to bear a substantial share of the cost of raising children (i.e., by contributing to the cost of daycare) compared to the case where the default is that children are cared for at home by the mother. In Section III, we explicitly consider the interaction of market-based child care with the parents' cost shares in raising children, and consider policies that can shift the cost shares. Here, we simply take the breakdown of the cost as given, and consider how fertility intentions and outcomes depend on this breakdown.

To gain intuition for how fertility depends on the distribution of child costs, it is useful to consider the case of independent distributions $F_{f}\left(v_{f}\right)$ and $F_{m}\left(v_{m}\right)$ for female and male child preferences, so that $F\left(v_{f}, v_{m}\right)=F_{f}\left(v_{f}\right) F_{m}\left(v_{m}\right)$. Expected fertility can then be written as:

$$
E(b)=1-F_{f}\left(\tilde{v}_{f}\right)-F_{m}\left(\tilde{v}_{m}\right)+F_{f}\left(\tilde{v}_{f}\right) F_{m}\left(\tilde{v}_{m}\right)
$$

Now consider, for a constant total cost of children $\phi$, the effect of a marginal increase in the female cost share $\chi_{f}$ and a corresponding decrease in the male share $\chi_{m}=1-\chi_{f}$. If the distribution functions are differentiable at $\tilde{v}_{f}$ and $\tilde{v}_{m}$, the marginal impact of a such a shift in the distribution of the burden of child care is:

$$
\frac{\partial E(b)}{\partial \chi_{f}}=\phi F_{m}^{\prime}\left(\tilde{v}_{m}\right)\left[1-F_{f}\left(\tilde{v}_{f}\right)\right]-\phi F_{f}^{\prime}\left(\tilde{v}_{f}\right)\left[1-F_{m}\left(\tilde{v}_{m}\right)\right] .
$$


The first (positive) term represents the increase in the number of men who agree to have a child if the female cost share $\chi_{f}$ increases (and hence the male cost share declines), and the second (negative) term is the decline in agreement on the part of women. The first term has two components: $F_{m}^{\prime}\left(\tilde{v}_{m}\right)$ is the density of the distribution of male child preferences at the cutoff, which tells us how many men switch from disagreeing to agreeing with having a child as $\chi_{f}$ rises. The second component $1-F_{f}\left(\tilde{v}_{f}\right)$ is the fraction of women who agree to have children. This term appears because the man switching from disagreeing to agreeing only results in a birth if the woman also agrees. If most women are opposed to having a child, an increase in male agreement has only a small effect on fertility. In the same way, the negative impact of a decline in female agreement on fertility, measured by $F_{f}^{\prime}\left(\tilde{v}_{f}\right)$, is weighted by the share of men agreeing to have a child $\left[1-F_{m}\left(\tilde{v}_{m}\right)\right]$.

The terms for the existing fractions of women and men agreeing to have a child in (A10) introduce a force that leads to high fertility if agreement on having children is balanced between the genders. In the extreme, if all women were opposed to having a baby but at least some men wanted one, the only way to raise fertility would be to lower the female cost share (and vice versa if all men were opposed). Given that we observe that in low-fertility countries women are more likely to be opposed to having another child compared to men, this suggests that fertility could be raised by lowering women's cost share. However, the overall distribution of child preferences is also important, because fertility reacts strongly only if many women are close to the threshold of wanting to have children.

The overall relationships between cost shares, agreement rates, and fertility can be fully characterized when child preferences are uniform, so that the densities $F_{f}^{\prime}\left(\tilde{v}_{f}\right)$ and $F_{m}^{\prime}\left(\tilde{v}_{m}\right)$ are constant. In particular, if female and male fertility preferences have the same uniform densities (but potentially different means), fertility is maximized when equal fractions of women and men agree to having a child. If one gender has more concentrated fertility preferences (higher density), fertility is maximized at a point where the rate of agreement in this gender is proportionately higher also. To formally establish this result, we first focus on the case of independent uniform distributions.

Proposition A1 (Effect of Distribution of Child Cost on Fertility Rate). Assume that the female and male child preferences follow independent uniform distributions with means $\mu_{g}$ and densities $d_{g}$ for $g \in\{f, m\}$. Then expected fertility $E(b)$ is a concave function of the female cost share $\chi_{f}$, and fertility is maximized at:

$$
\hat{\chi}_{f}=\min \left\{1, \max \left\{0, \frac{1}{2}+\frac{1}{2 \phi}\left[\mu_{f}-\mu_{m}+\frac{1}{2} \frac{d_{m}-d_{f}}{d_{f} d_{m}}\right]\right\}\right\} .
$$

Hence, if women and men have the same preferences $\left(\mu_{f}=\mu_{m}, d_{f}=d_{m}\right)$, fertility is maximized when the child care burden is shared equally. Moreover, if the distributions of female and male preferences have the same density $\left(d_{f}=d_{m}\right)$, equal shares of men and women agree to having a child at the maximum 
fertility rate, even if $\mu_{f} \neq \mu_{m}$ (provided that $\hat{\chi}_{f}$ is interior). If $d_{f} \neq d_{m}$, at $\hat{\chi}_{f}$ more individuals of the gender with the more concentrated distribution of preferences (higher $d_{g}$ ) agree to having a child than individuals of the gender with more dispersed preferences. Specifically, fertility is maximized when the ratio of agreement shares $\left(1-F_{f}\left(\tilde{v}_{f}\right)\right) /\left(1-F_{m}\left(\tilde{v}_{m}\right)\right)$ is equal to the ratio of densities $d_{f} / d_{g}$.

Proof of Proposition A1: Fertility preferences for gender $g \in\{f, m\}$ have independent uniform density on $\mu_{g}-\left(d_{g}\right)^{-1} / 2, \mu_{g}+\left(d_{g}\right)^{-1} / 2$. The distribution function is given by (in the relevant range):

$$
F\left(v_{f}, v_{m}\right)=\left(v_{f}-\left(\mu_{f}-\frac{1}{2 d_{f}}\right)\right) d_{f}\left(v_{m}-\left(\mu_{m}-\frac{1}{2 d_{m}}\right)\right) d_{m}
$$

and the fraction of couples who have a child is given by:

$$
\begin{aligned}
E(b)=1-\left(\tilde{v}_{f}-\left(\mu_{f}-\frac{1}{2 d_{f}}\right)\right) & d_{f}-\left(\tilde{v}_{m}-\left(\mu_{m}-\frac{1}{2 d_{m}}\right)\right) d_{m} \\
& +\left(\tilde{v}_{f}-\left(\mu_{f}-\frac{1}{2 d_{f}}\right)\right) d_{f}\left(\tilde{v}_{m}-\left(\mu_{m}-\frac{1}{2 d_{m}}\right)\right) d_{m} .
\end{aligned}
$$

Given (A6) and (A7), the average fertility rate is a quadratic and concave function of the female cost share $\chi_{f}$ (i.e., the quadratic term has a negative sign). The derivative of average fertility with respect to $\chi_{f}$ is:

$$
\begin{aligned}
\frac{\partial E(b)}{\partial \chi_{f}}=\phi d_{m}\left[1-\left(\left(\chi_{f}+\alpha / 2\right) \phi\right.\right. & \left.\left.-\left(\mu_{f}-\frac{1}{2 d_{f}}\right)\right) d_{f}\right] \\
& -\phi d_{f}\left[1-\left(\left(1-\chi_{f}+\alpha / 2\right) \phi-\left(\mu_{m}-\frac{1}{2 d_{m}}\right)\right) d_{m}\right]
\end{aligned}
$$

which simplifies to:

$$
\frac{\partial E(b)}{\partial \chi_{f}}=\phi\left(d_{m}-d_{f}\right)+\phi d_{f} d_{m}\left[\left(1-2 \chi_{f}\right) \phi+\mu_{f}-\mu_{m}+\frac{1}{2}\left(\frac{1}{d_{m}}-\frac{1}{d_{f}}\right)\right] .
$$

Equating the right-hand side to zero gives the cost share $\hat{\chi}_{f}$ at which fertility is maximized (assuming that the solution is interior):

$$
\hat{\chi}_{f}=\frac{1}{2}+\frac{1}{2 \phi}\left[\mu_{f}-\mu_{m}+\frac{1}{2} \frac{d_{m}-d_{f}}{d_{f} d_{m}}\right] .
$$

Taking corner solutions into account, the fertility maximizing cost share is given by expression (A11) in the statement of the proposition. Moreover, starting with (A13), if there is an interior 
maximum we have:

$$
\begin{aligned}
\phi d_{m}\left[1-\left(\left(\hat{\chi}_{f}+\alpha / 2\right) \phi-\left(\mu_{f}-\frac{1}{2 d_{f}}\right)\right)\right. & \left.d_{f}\right] \\
& =\phi d_{f}\left[1-\left(\left(1-\hat{\chi}_{f}+\alpha / 2\right) \phi-\left(\mu_{m}-\frac{1}{2 d_{m}}\right)\right) d_{m}\right],
\end{aligned}
$$

and hence:

$$
\frac{d_{f}}{d_{m}}=\frac{1-\left(\left(\hat{\chi}_{f}+\alpha / 2\right) \phi-\left(\mu_{f}-\frac{1}{2 d_{f}}\right)\right) d_{f}}{1-\left(\left(1-\hat{\chi}_{f}+\alpha / 2\right) \phi-\left(\mu_{m}-\frac{1}{2 d_{m}}\right)\right) d_{m}}=\frac{1-F_{f}\left(\tilde{v}_{f}\right)}{1-F_{m}\left(\tilde{v}_{m}\right)} .
$$

Thus, as stated in the last part of the proposition, if the distributions of female and male child preferences have different densities, fertility is maximized if the ratio of densities is equal to the fraction of individuals agreeing to have a child for each gender.

The result suggests that if the distribution of the child care burden is not at the fertility-maximizing level, the fertility rate could be raised by policies that shift these responsibilities in a particular direction. Likewise, subsidies for childbearing would be more or less effective depending on whether they specifically target one of the partners (say, by providing publicly financed alternatives for tasks that previously fell predominantly on one partner). For a concrete policy analysis, we need to add more structure to the analysis. We do this in Section III in a more elaborate quantitative version of our theory. When matched to the GGP data, that model indeed predicts that the effectiveness of policies designed to promote childbearing crucially depends on how the policies are targeted.

For non-uniform distributions of child preferences, the same intuitions regarding the effects of a change in cost shares that arise from Proposition A1 still apply locally. In particular, given (A10), the local effect of a change in cost shares is driven by the density of the child preferences of each gender and by the existing shares of agreement and disagreement by gender. Global results can be obtained only by placing at least some restrictions on the overall shape of preferences. ${ }^{1}$ Empirically, we do not have information on the global shape of child preferences away from the cutoffs, because we observe only a binary variable on child preferences. We therefore use uniform distributions in the quantitative implementation of the dynamic model, while noting that the measured effects should be considered to be locally valid.

In the quantitative model, we also allow for correlation in child preferences within households.

\footnotetext{
${ }^{1}$ One can even construct cases (albeit unrealistic ones) where fertility is maximized when one gender bears the entire child care burden. For example, consider a preference distribution (identical between men and women) where 50 percent of each gender want to have a child even if they have to bear the entire child cost, whereas the other 50 percent agree to having a child only if they bear none of the cost. In this case, 50 percent of couples have a child if one partner bears all the cost, whereas only 25 percent of couples have a child if both partners make a contribution.
} 
We now show that results similar to those in Proposition A1 (which was established for the case of independent child preferences) also go through when we allow for correlation in child preferences between the partners.

Proposition A2 (Effect of Distribution of Child Cost with Correlated Preferences). Assume that the female and male child preferences follow uniform distributions with means $\mu_{g}$ and densities $d_{g}$ for $g \in\{f, m\}$. With probability $\eta>0$, the draw of a given woman and man are perfectly correlated in the sense that:

$$
v_{f}=\frac{d_{m}}{d_{f}}\left(v_{m}-\mu_{m}\right)+\mu_{f} .
$$

With probability $1-\eta$, woman and man have independent draws from the their distributions. This implies that $\eta$ is the correlation between the woman's and the man's child preference. Then expected fertility $E(b)$ is a concave function of the female cost share $\chi_{f}$, and fertility is maximized at:

$$
\hat{\chi}_{f}=\min \left\{1, \hat{\chi}_{f 1}, \max \left\{0, \bar{\chi}_{f}, \hat{\chi}_{f 2}\right\}\right\}
$$

where

$$
\begin{gathered}
\bar{\chi}_{f}=\frac{\left(d_{m}+\frac{\alpha}{2}\left(d_{m}-d_{f}\right)\right) \phi+\mu_{f} d_{f}-\mu_{m} d_{m}}{\phi\left(d_{f}+d_{m}\right)}, \\
\hat{\chi}_{f 1}=\frac{1}{2}+\frac{1}{2 \phi}\left[\mu_{f}-\mu_{m}+\frac{1}{2}\left(\frac{\frac{1+\eta}{1-\eta} d_{m}-d_{f}}{d_{f} d_{m}}\right)\right], \\
\hat{\chi}_{f 2}=\frac{1}{2}+\frac{1}{2 \phi}\left[\mu_{f}-\mu_{m}+\frac{1}{2}\left(\frac{d_{m}-\frac{1+\eta}{1-\eta} d_{f}}{d_{f} d_{m}}\right)\right] .
\end{gathered}
$$

Hence, if women and men have the same preferences $\left(\mu_{f}=\mu_{m}, d_{f}=d_{m}\right)$, fertility is maximized when the child care burden is equally shared, $\hat{\chi}_{f}=0.5$. Moreover, if the distributions of female and male preferences have the same density $\left(d_{f}=d_{m}\right)$, equal shares of men and women agree to having a child at the maximum fertility rate, even if $\mu_{f} \neq \mu_{m}$ (provided that $\hat{\chi}_{f}$ is interior). If $d_{f} \neq d_{m}$ and $\hat{\chi}_{f} \neq \bar{\chi}_{f}$, at $\hat{\chi}_{f}$ more individuals of the gender with the more concentrated distribution of preferences (higher $d_{g}$ ) agree to having a child than individuals of the gender with more dispersed preferences.

Proof of Proposition A2: Fertility preferences for gender $g \in\{f, m\}$ have uniform density on $\mu_{g}-\left(d_{g}\right)^{-1} / 2, \mu_{g}+\left(d_{g}\right)^{-1} / 2$. With probability $\eta$, the draws are perfectly correlated in the sense that we have:

$$
v_{f}=\frac{d_{m}}{d_{f}}\left(v_{m}-\mu_{m}\right)+\mu_{f}
$$

and with probability $1-\eta$ the draws are independent. The distribution function is given by (in 
the relevant range):

$$
\begin{aligned}
F\left(v_{f}, v_{m}\right)=\eta \min \left\{\left(v_{f}-\left(\mu_{f}-\frac{1}{2 d_{f}}\right)\right) d_{f},\left(v_{m}-\left(\mu_{m}-\frac{1}{2 d_{m}}\right)\right) d_{m}\right\} \\
+(1-\eta)\left(v_{f}-\left(\mu_{f}-\frac{1}{2 d_{f}}\right)\right) d_{f}\left(v_{m}-\left(\mu_{m}-\frac{1}{2 d_{m}}\right)\right) d_{m} .
\end{aligned}
$$

The fraction of couples who have a child is given by:

$$
\begin{gathered}
E(b)=1-\eta \max \left\{\left(\tilde{v}_{f}-\left(\mu_{f}-\frac{1}{2 d_{f}}\right)\right) d_{f},\left(\tilde{v}_{m}-\left(\mu_{m}-\frac{1}{2 d_{m}}\right)\right) d_{m}\right\} \\
-(1-\eta)\left(\left(\tilde{v}_{f}-\left(\mu_{f}-\frac{1}{2 d_{f}}\right)\right) d_{f}+\left(\tilde{v}_{m}-\left(\mu_{m}-\frac{1}{2 d_{m}}\right)\right) d_{m}\right) \\
\quad+(1-\eta)\left(\tilde{v}_{f}-\left(\mu_{f}-\frac{1}{2 d_{f}}\right)\right) d_{f}\left(\tilde{v}_{m}-\left(\mu_{m}-\frac{1}{2 d_{m}}\right)\right) d_{m} .
\end{gathered}
$$

Given (A6) and (A7), the average fertility rate as a function of the female cost share $\chi_{f}$ has a kink at the point where the two elements inside the max operator are equal, and is a quadratic and concave function of $\chi_{f}$ away from the kink. The kink is at the cost share that equates disagreement between men and women, given by:

$$
\bar{\chi}_{f}=\frac{\left(d_{m}+\frac{\alpha}{2}\left(d_{m}-d_{f}\right)\right) \phi+\mu_{f} d_{f}-\mu_{m} d_{m}}{\phi\left(d_{f}+d_{m}\right)} .
$$

For $\chi_{f}<\bar{\chi}_{f}$, the derivative of fertility with respect to $\chi_{f}$ is given by:

$$
\begin{aligned}
\left.\frac{\partial E(b)}{\partial \chi_{f}}\right|_{\chi_{f}<\bar{\chi}_{f}}=\eta \phi d_{m}+ & (1-\eta) \phi d_{m}\left[1-\left(\left(\chi_{f}+\alpha / 2\right) \phi-\left(\mu_{f}-\frac{1}{2 d_{f}}\right)\right) d_{f}\right] \\
& -(1-\eta) \phi d_{f}\left[1-\left(\left(1-\chi_{f}+\alpha / 2\right) \phi-\left(\mu_{m}-\frac{1}{2 d_{m}}\right)\right) d_{m}\right],
\end{aligned}
$$

which simplifies to:

$$
\left.\frac{\partial E(b)}{\partial \chi_{f}}\right|_{\chi_{f}<\bar{\chi}_{f}}=\phi\left(d_{m}-(1-\eta) d_{f}\right)+(1-\eta) \phi d_{f} d_{m}\left[\left(1-2 \chi_{f}\right) \phi+\mu_{f}-\mu_{m}+\frac{1}{2}\left(\frac{1}{d_{m}}-\frac{1}{d_{f}}\right)\right] .
$$

Equating the right-hand side to zero gives the cost share $\hat{\chi}_{f 1}$ would be maximized fertility is maximized if the solution is interior and if we have $\hat{\chi}_{f 1}<\bar{\chi}_{f}$ :

$$
\hat{\chi}_{f 1}=\frac{1}{2}+\frac{1}{2 \phi}\left[\mu_{f}-\mu_{m}+\frac{1}{2}\left(\frac{\frac{1+\eta}{1-\eta} d_{m}-d_{f}}{d_{f} d_{m}}\right)\right] .
$$


In the alternative case of $\chi_{f}>\bar{\chi}_{f}$, the derivative of fertility with respect to $\chi_{f}$ is given by:

$$
\begin{aligned}
\left.\frac{\partial E(b)}{\partial \chi_{f}}\right|_{\chi_{f}>\bar{\chi}_{f}}=-\eta \phi d_{f}+ & (1-\eta) \phi d_{m}\left[1-\left(\left(\chi_{f}+\alpha / 2\right) \phi-\left(\mu_{f}-\frac{1}{2 d_{f}}\right)\right) d_{f}\right] \\
& -(1-\eta) \phi d_{f}\left[1-\left(\left(1-\chi_{f}+\alpha / 2\right) \phi-\left(\mu_{m}-\frac{1}{2 d_{m}}\right)\right) d_{m}\right]
\end{aligned}
$$

which simplifies to:

$$
\left.\frac{\partial E(b)}{\partial \chi_{f}}\right|_{\chi_{f}>\bar{\chi}_{f}}=\phi\left((1-\eta) d_{m}-d_{f}\right)+(1-\eta) \phi d_{f} d_{m}\left[\left(1-2 \chi_{f}\right) \phi+\mu_{f}-\mu_{m}+\frac{1}{2}\left(\frac{1}{d_{m}}-\frac{1}{d_{f}}\right)\right] .
$$

Equating the right-hand side to zero gives the cost share $\hat{\chi}_{f 2}$ would be maximized fertility is maximized if the solution is interior and if we have $\hat{\chi}_{f 2}>\bar{\chi}_{f}$ :

$$
\hat{\chi}_{f 2}=\frac{1}{2}+\frac{1}{2 \phi}\left[\mu_{f}-\mu_{m}+\frac{1}{2}\left(\frac{d_{m}-\frac{1+\eta}{1-\eta} d_{f}}{d_{f} d_{m}}\right)\right] .
$$

We have $\hat{\chi}_{f 1}>\hat{\chi}_{f 2}$. Three cases are possible. If $\hat{\chi}_{f 2} \leq \bar{\chi}_{f} \leq \hat{\chi}_{f 1}$, fertility is maximized at the kink $\bar{\chi}_{f}$, and equal numbers of men and women agree to have a child. If $\hat{\chi}_{f 1}<\bar{\chi}_{f}$, fertility is maximized at $\hat{\chi}_{f 1}$, and if $\hat{\chi}_{f 2}>\bar{\chi}_{f}$, fertility is maximized at $\hat{\chi}_{f 2}$. Taking also the possible corners at 0 and 1 into account, the fertility maximizing cost share $\hat{\chi}_{f}$ can be written as:

$$
\hat{\chi}_{f}=\min \left\{1, \hat{\chi}_{f 1}, \max \left\{0, \bar{\chi}_{f}, \hat{\chi}_{f 2}\right\}\right\}
$$

as stated in expression (A15) in the proposition.

With identical preferences, we have $\hat{\chi}_{f 2}<\bar{\chi}_{f}=0.5<\hat{\chi}_{f 1}$, so that $\hat{\chi}_{f}=0.5$. When $d_{f}=d_{m}$, we still have $\hat{\chi}_{f 2}<\bar{\chi}_{f}<\hat{\chi}_{f 1}$, so that in an interior solution $\hat{\chi}_{f}=\bar{\chi}_{f}$ implying (by the construction of $\bar{\chi}_{f}$ ) that equal frictions of men and women agree to have a child. As the final case, consider the situation when $d_{m}>d_{f}$ (the case $d_{m}<d_{f}$ is parallel and omitted). We want to show that at the fertility maximizing cost share $\hat{\chi}_{f}$, at least as many men agree to having a child as women do. Because equal fractions agree at $\chi_{f}=\bar{\chi}_{f}$, we need to show that $\hat{\chi}_{f} \geq \bar{\chi}$. To construct a contradiction argument, assume to the contrary that $\hat{\chi}_{f}<\bar{\chi}$. If there is an interior maximum in this region it is given by $\hat{\chi}_{f 1}$. The first order condition corresponding to this case gives:

$$
(1-\eta) \phi d_{f}\left[1-F\left(\tilde{v}_{m}\right)\right]=\eta \phi d_{m}+(1-\eta) \phi d_{m}\left[1-F\left(\tilde{v}_{f}\right)\right]
$$

which implies:

$$
1>\frac{d_{f}}{d_{m}}>\frac{1-F\left(\tilde{v}_{f}\right)}{1-F\left(\tilde{v}_{m}\right)}
$$


Thus, fewer women than men would agree to having a child; however, this is a contradiction because $\hat{\chi}_{f}<\bar{\chi}$ implies that more women than men agree to have a child. Hence, when $d_{m}>d_{f}$ we must have $\hat{\chi}_{f} \geq \bar{\chi}_{f}$, which establishes the last claim in the proposition.

\section{The Timing of Births}

In this appendix we illustrate the role of the persistence of fertility preferences for determining the overall fertility rate. A limitation of the static model used in the theoretical part of the paper is that it does not distinguish between the timing of births and the total number of births. In a dynamic setting, there is an important distinction between partners' disagreement about the total number of children they want to have, and disagreement about when to have them. In the extreme, one can envision a setting in which all couples agree on how many children they ultimately want to have, and the only source of conflict is whether to have them early or late. In this case, an intervention that reshuffles the child care burden between the partners may affect when people have children, but it would not affect the ultimate outcome in terms of the total number of children per couple. If the policy aim is to raise fertility rates, understanding whether policy affects total fertility or only the timing of fertility is clearly important.

We now extend the theoretical analysis to a two-period setting in order to clarify how this issue relates to the persistence of child preferences between periods. In the quantitative model introduced in Section III in the main text, we use repeated observations of the child preferences of a given couple from multiple waves of the GGP survey to pin down this critical aspect of the analysis.

In the setting considered here, there is a continuum of couples, and the wages $w_{f}$ and $w_{m}$, the child cost $\phi$, and the cost shares $\chi_{f}$ and $\chi_{m}=1-\chi_{f}$ are identical across couples and over the two periods $t=1,2$. The child cost accrues only in the period when a child is born (to be relaxed in Section III). Preferences are as in (1), but extending over two periods with discount factor $\beta$, where $0<\beta \leq 1$. Child preferences in the second period may depend on the fertility outcome in the first period. First-period child preferences are denoted as $v_{f, 1}, v_{m, 1}$, and second-period preferences are given by $v_{f, 2}$ and $v_{m, 2}$. Hence, the expected utility function is:

$$
E\left[u_{g}\left(c_{g, 1}, b_{1}, c_{g, 2}, b_{2}\right)\right]=c_{g, 1}+b_{1} v_{g, 1}+\beta E\left[c_{g, 2}+b_{2} v_{g, 2} \mid b_{1}\right]
$$

The expectations operator appears because we allow for the possibility that child preferences in the second period are realized only after decisions are made in the first period. As before, we focus on the case of lack of commitment. In each period, the partners bargain ex post over consumption after the fertility decision has been made; in addition, the partners are unable to commit to a specific second-period consumption allocation during the first period. There is no 
savings technology, so that (in the case of cooperation) the per-period budget constraints are as in (2). In addition, the outside option of non-cooperation affects only a single period. That is, a non-cooperating couple in the first period returns to cooperation in the second period.

The second period of the two-period model is formally identical to the static model, and Propositions 2 and A1 apply. For a given couple with a given preference draw, let $E V_{f, 2}(0)$ and $E V_{m, 2}(0)$ denote equilibrium second-period expected utilities conditional on no child being born in the first period, and $E V_{f, 2}(1)$ and $E V_{m, 2}(1)$ denote expected utilities if there is a first-period birth. Here the dependence of second-period utility on first-period fertility is solely due to preferences in the second period being allowed to depend on the fertility outcome in the first period. We start by characterizing the conditions for births to take place.

Proposition A3 (Conditions for Child Birth in Two-Period Model). In the second period, a birth takes place $\left(b_{2}=1\right)$ if and only if the following conditions are satisfied:

$$
\begin{aligned}
v_{f, 2} \geq\left(\chi_{f}+\frac{\alpha}{2}\right) \phi & \equiv \tilde{v}_{f, 2}, \\
v_{m, 2} \geq\left(\chi_{m}+\frac{\alpha}{2}\right) \phi & \equiv \tilde{v}_{m, 2} .
\end{aligned}
$$

In the first period, a birth takes place $\left(b_{1}=1\right)$ if and only if the following conditions are met:

$$
\begin{aligned}
v_{f, 1} & \geq\left(\chi_{f}+\frac{\alpha}{2}\right) \phi+\beta\left(E V_{f, 2}(0)-E V_{f, 2}(1)\right) \equiv \tilde{v}_{f, 1} \\
v_{m, 1} & \geq\left(\chi_{m}+\frac{\alpha}{2}\right) \phi+\beta\left(E V_{m, 2}(0)-E V_{m, 2}(1)\right) \equiv \tilde{v}_{m, 1}
\end{aligned}
$$

Proof of Proposition A3: The second period of the two-period model is formally identical to the static model analyzed in Proposition 2, and hence conditions (7) and (8) are applicable, which gives (A19) and (A20). The expected utilities in period 2 as a function of first-period utility are then given by:

$$
\begin{aligned}
V_{g}\left(b_{1}\right)= & \int_{v_{f, 2}} \int_{v_{m, 2}}\left[w_{g}+\frac{\alpha}{2}\left(w_{f}+w_{m}\right)\right. \\
& \left.+I\left(v_{f, 2} \geq \tilde{v}_{f, 2}, v_{m, 2} \geq \tilde{v}_{m, 2}\right)\left(v_{g, 2}-\left(\chi_{g}+\frac{\alpha}{2}\right) \phi\right)\right] f\left(v_{f, 2}, v_{m, 2} \mid b_{1}\right) d v_{f, 2} d v_{m, 2}
\end{aligned}
$$

where $f\left(v_{f, 2}, v_{m, 2} \mid b_{1}\right)$ is the joint density of fertility preferences in the second period given $b_{1}$. Given these utilities, the terms $E V_{g}(1)-E V_{g}(0)$ then represent the change in second period expected utility as a function of the initial fertility choice. From the perspective of deciding on fertility in the first period, these terms act like a constant that adds to (or subtract from) the benefit of children. Applying Proposition 2, the conditions for having a baby in the first period 
are then:

$$
\begin{gathered}
v_{f, 1}+\beta\left(E V_{f}(1)-E V_{f}(0)\right) \geq\left(\chi_{f}+\frac{\alpha}{2}\right) \phi, \\
v_{m, 1}+\beta\left(E V_{m}(1)-E V_{m}(0)\right) \geq\left(\chi_{m}+\frac{\alpha}{2}\right) \phi,
\end{gathered}
$$

which gives (A21) and (A22).

Hence, the main change compared to the static case is that when deciding on fertility in the first period, the partners also take into account how having a child affects their utility in the second period. Depending on how preferences evolve, this effect could go in either direction. If future preferences are uncertain, there can be an option value of waiting, i.e., a couple may delay having a child in the hope of a more favorable future preference realization.

We now illustrate how the evolution of child preferences determines whether shifts in the distribution of the child care burden (say, induced by targeted policies) affect the total number of children (denoted by $n=b_{1}+b_{2}$ ) or just the timing of fertility. We do so by considering two polar cases. The first one is where first-period fertility does not affect preferences in the second period; instead, fertility preferences are drawn repeatedly from the same distribution. In this scenario, shifts in the cost share affect only total fertility, but not the timing of fertility.

Proposition A4 (Level and Timing of Fertility with Independent Draws). Assume that in both periods, the female and male child preferences follow independent uniform distributions with identical means $\mu_{g}$ and densities $d_{g}$ for $g \in\{f, m\}$. Then expected fertility $E\left(b_{1}\right)$ and $E\left(b_{2}\right)$ in the two periods depends on the female cost share $\chi_{f}$ as described in Proposition A1. For any $\chi_{f}$, we also have $E\left(b_{1}\right)=$ $E\left(b_{2}\right)$, so that total expected lifetime fertility $E(n)=E\left(b_{1}\right)+E\left(b_{2}\right)$ satisfies:

$$
E(n)=2 E\left(b_{1}\right)=2 E\left(b_{2}\right) .
$$

The timing of fertility, as measured by the ratio $E\left(b_{1}\right) / E\left(b_{2}\right)$, is independent of $\chi_{f}$.

Proof of Proposition A4: Given that fertility preferences in the second period do not depend on the fertility realization in the first period, we have $E V_{f}(0)=E V_{f}(1)$ and $E V_{m}(0)=E V_{m}(1)$. Hence, given Proposition A3 the conditions for fertility in each period are the same as those for the single period model characterized in Proposition 2. We therefore obtain the same fertility rate in both periods, $E\left(b_{1}\right)=E\left(b_{2}\right)$, and Proposition A1 applies to each period separately.

Next, we consider an opposite polar case where having a child in the first period removes the desire for additional children.

Proposition A5 (Level and Timing of Fertility with Fixed Desire for Children). Assume that in the first period, the female and male child preferences follow independent uniform distributions with means 
$\mu_{g}$ and densities $d_{g}$ for $g \in\{f, m\}$. In the second period, preferences depend on first-period fertility: if $b_{1}=1$, we have $v_{f, 2}=v_{m, 2}=0$, and if $b_{1}=0$, we have $v_{g, 2}=\left(\chi_{g}+\alpha\right) \phi$. Then the total fertility rate is constant for all $\chi_{f} \in[0,1]$ :

$$
E(n)=E\left(b_{1}\right)+E\left(b_{2}\right)=1 .
$$

Fertility in the first period depends on $\chi_{f}$ as described in Proposition A1 for the transformed parameter $\tilde{\alpha}=(1+\beta) \alpha$. Given that $E(n)$ is constant and:

$$
\frac{E\left(b_{1}\right)}{E\left(b_{2}\right)}=\frac{E\left(b_{1}\right)}{1-E\left(b_{1}\right)}
$$

the cost share $\chi_{f}$ affects only the timing, but not the level of fertility.

Proof of Proposition A5: We proceed by backward induction. If $b_{1}=1$, we have $v_{f, 2}=v_{m, 2}=0$. Given (A19) and (A20), this guarantees that no additional child will be born in the second period, and second-period utilities are (given Nash bargaining):

$$
\begin{aligned}
& E V_{f}(1)=w_{f}+\frac{\alpha}{2}\left(w_{f}+w_{m}\right), \\
& E V_{m}(1)=w_{m}+\frac{\alpha}{2}\left(w_{f}+w_{m}\right)
\end{aligned}
$$

Conversely, if we have $b_{1}=0$, the preference realizations $v_{g, 2}=\left(\chi_{g}+\alpha\right) \phi$ guarantees that the conditions (A19) and (A20) are satisfied, so that $b_{2}=1$ for sure. We therefore have $b_{2}=1-b_{1}$ and, in expectation:

$$
E\left(b_{2}\right)=1-E\left(b_{1}\right)
$$

which gives (A24) and (A25). Continuing, the resulting second-period utilities conditional on $b_{1}=0$ are:

$$
\begin{gathered}
E V_{f}(0)=w_{f}-\chi_{f} \phi+\frac{\alpha}{2}\left(w_{f}+w_{m}-\phi\right)+\left(\chi_{f}+\alpha\right) \phi \\
E V_{m}(0)=w_{m}-\chi_{m} \phi+\frac{\alpha}{2}\left(w_{f}+w_{m}-\phi\right)+\left(\chi_{m}+\alpha\right) \phi
\end{gathered}
$$

which can be simplified to:

$$
\begin{aligned}
& E V_{f}(0)=w_{f}+\frac{\alpha}{2}\left(w_{f}+w_{m}+\phi\right), \\
& E V_{m}(0)=w_{m}+\frac{\alpha}{2}\left(w_{f}+w_{m}+\phi\right)
\end{aligned}
$$


Given these utilities, the impact of having a child in the first period on continuation utility is:

$$
\begin{aligned}
E V_{f}(0)-E V_{f}(1) & =\frac{\alpha}{2} \phi, \\
E V_{m}(0)-E V_{f}(1) & =\frac{\alpha}{2} \phi .
\end{aligned}
$$

We now move to the fertility decision in the first period. The conditions (A21) and (A22) are:

$$
\begin{aligned}
v_{f, 1} & \geq\left(\chi_{f}+\frac{\alpha}{2}\right) \phi+\beta \frac{\alpha}{2} \phi \\
v_{m, 1} & \geq\left(1-\chi_{f}+\frac{\alpha}{2}\right) \phi+\beta \frac{\alpha}{2} \phi .
\end{aligned}
$$

which can be rewritten as

$$
\begin{aligned}
v_{f, 1} & \geq\left(\chi_{f}+(1+\beta) \frac{\alpha}{2}\right) \phi \\
v_{m, 1} & \geq\left(1-\chi_{f}+(1+\beta) \frac{\alpha}{2}\right) \phi .
\end{aligned}
$$

With the change of variables

$$
\tilde{\alpha}=(1+\beta) \alpha,
$$

the conditions can be written as:

$$
\begin{aligned}
v_{f, 1} \geq & \left(\chi_{f}+\frac{\tilde{\alpha}}{2}\right) \phi \\
v_{m, 1} \geq & \left(1-\chi_{f}+\frac{\tilde{\alpha}}{2}\right) \phi .
\end{aligned}
$$

The conditions therefore are of the form (7) and (8), so that the results in Proposition A1 apply with the transformed parameter $\tilde{\alpha}$.

The proposition captures an extreme case where all individuals eventually want to end up with exactly one child, and the only disagreement is over when that child should be born. But the intuition from this example carries over to the general case where a birth leads to at least some downward shift in future fertility preferences. This is a plausible scenario, because as long as the marginal utility derived from children is diminishing, some such downward shift will be present. If this effect is strong, policies that aim to shift the distribution of the child care burden may have little impact on the overall fertility rate, even when the data in a given cross section suggest a lot of disagreement over fertility.

To deal with this issue and to allow for a meaningful policy analysis, we need to capture how a given couple's child preferences shift over time, and how this depends on child birth. Doing 
this in a quantitatively plausible manner requires a more elaborate model, which we develop in Section III in the main text.

\section{Fertility Choice with Partial Commitment}

In this appendix, we consider an extension of the basic setup that allows for partial commitment. The partial-commitment setup also forms the basis for the quantitative model developed in Section III in the main text. In this version of the model, the cost shares $\chi_{f}$ and $\chi_{m}$ are not parameters, but choice variables. Before deciding on fertility, but after learning about their child preferences, the partners can take an action that changes the ex-post distribution of the child care burden. Formally, the cost share $\chi_{f}$ is selected from a given feasible interval $\left[\chi_{f, \min }, \chi_{f, \max }\right]$, with $\chi_{m}=1-\chi_{f}$. There is also a default cost share $\chi_{f, 0} \in\left[\chi_{f, \min }, \chi_{f, \max }\right]$. Intuitively, what we have in mind is that couples can commit to some long-term decisions that affect the ex-post child care burden. Examples include a choice of location that affects the availability of child care (i.e., close to grandparents or a daycare facility), and buying durable goods (such as household appliances or minivans) that facilitate taking care of children. Such decisions would lower the expected time cost of having children and turn those into monetary expenses, which implicitly lowers the child care burden on the partner who ex post will be responsible for the majority of the time costs of raising children. We show that as long as the ex-post cost shares can be moved only within a limited range, the partial commitment model has the same qualitative implications as the setup with fixed cost shares considered above.

The time line of events and decisions is as follows.

1. The potential utilities from having a child $v_{f}$ and $v_{m}$ are realized.

2. The woman can offer to increase her child care burden $\chi_{f}$ above the default within the feasible range, $\chi_{f, 0}<\chi_{f} \leq \chi_{f, \max }$.

3. The man can offer to increase his child care burden $1-\chi_{f}$ above the default within the feasible range, $\chi_{f, \min } \leq \chi_{f}<\chi_{f, 0}$.

4. Given the final $\chi_{f}$ arising from the previous stage, the couple decides on whether to have a child as before.

5. Given the decisions in the previous rounds, the couple decides on the consumption allocation as before.

Consistent with our treatment of fertility choice, we assume that agreement is necessary to move cost shares; the partners can make voluntary offers to do more work, but they cannot unilaterally force the other partner to do more. We can solve for the equilibrium by backward induction. Stages 4 and 5 are identical to the existing model; hence, we only need to characterize the 
decisions in Stages 2 and 3 of potentially altering ex-post child care arrangements, and hence bargaining power.

Proposition A6 (Fertility Choice under Partial Commitment). Under partial of commitment, a birth takes place if and only if the conditions:

$$
\begin{aligned}
v_{f}+v_{m} & \geq(1+\alpha) \phi, \\
v_{f} & \geq\left(\chi_{f, \text { min }}+\frac{\alpha}{2}\right) \phi, \\
v_{m} & \geq\left(1-\chi_{f, \max }+\frac{\alpha}{2}\right) \phi .
\end{aligned}
$$

are all satisfied. The first condition states that having a baby extends the utility possibility frontier for the couple, and the remaining conditions state that there is a $\chi_{f}$ in the feasible range such that both partners benefit from having the baby. In terms of predictions for fertility, partial commitment nests the cases of lack of commitment when $\chi_{f, \min }=\chi_{f, \max }$, and full commitment when the conditions:

$$
\begin{aligned}
\chi_{f, \min } & \leq \frac{\min \left(v_{f}\right)}{\phi}-\frac{\alpha}{2}, \\
\chi_{f, \max } & \geq 1-\frac{\min \left(v_{m}\right)}{\phi}+\frac{\alpha}{2}
\end{aligned}
$$

are satisfied.

Proof of Proposition A6: For a given $\chi_{f} \in\left[\chi_{f, \min }, \chi_{f, \max }\right]$ that is negotiated in Stages 1-3, the outcome of the last two stages is as in the lack of commitment model analyzed in Proposition 2. Hence, the utilities $u_{g}\left(b, \chi_{f}\right)$ that each partner attains are given by (A1), (A4), and (A5):

$$
\begin{aligned}
& u_{f}\left(0, \chi_{f}\right)=w_{f}+\frac{\alpha}{2}\left[w_{f}+w_{m}\right] \\
& u_{m}\left(0, \chi_{f}\right)=w_{m}+\frac{\alpha}{2}\left[w_{f}+w_{m}\right] \\
& u_{f}\left(1, \chi_{f}\right)=w_{f}+\frac{\alpha}{2}\left[w_{f}+w_{m}-\phi\right]+\left[v_{f}-\chi_{f} \phi\right] \quad \text { and } \\
& u_{m}\left(1, \chi_{f}\right)=w_{m}+\frac{\alpha}{2}\left[w_{f}+w_{m}-\phi\right]+\left[v_{m}-\chi_{m} \phi\right] .
\end{aligned}
$$

A child is born whenever both partners agree, i.e. as soon as

$$
v_{f} \geq\left(\chi_{f}+\frac{\alpha}{2}\right) \phi \quad \text { and } \quad v_{m} \geq\left(1-\chi_{f}+\frac{\alpha}{2}\right) \phi .
$$

We first show that (A26) to (A28) are necessary for a birth to take place. Summing the two inequalities in (A35) yields (A26); hence, (A26) is necessary for a child to be born. Intuitively, (A26) states that a baby can be born only if having a baby expands the couple's utility possibility frontier. Next, if (A27) is violated, we have $u_{f}\left(1, \chi_{f, \min }\right)<u_{f}\left(0, \chi_{f, \min }\right)$. Hence, the woman will 
be opposed to having a child even at her lowest possible cost share, and a fortiori for all other feasible cost shares as well. Hence, (A27) is necessary for the woman to agree to having a child. The same argument implies that (A28) is necessary for the man to agree to having a child.

Next, we want to show that (A26) to (A28) are sufficient for a birth to take place. Consider first the case where (A26) is satisfied and we also have:

$$
\begin{gathered}
v_{f} \geq\left(\chi_{f, 0}+\frac{\alpha}{2}\right) \phi \\
v_{m} \geq\left(1-\chi_{f, 0}+\frac{\alpha}{2}\right) \phi,
\end{gathered}
$$

i.e., (7) and (8) are satisfied at the default cost share $\chi_{f, 0}$ (this implies that (A27) and (A28) are also satisfied). Then, given Proposition 2, if neither partner offers to bear higher cost, the couple will have the child, and both partners will be better off compared to not having a child. Moreover, given (A33) and (A34), a partner offering to bear higher cost could only lower her or his utility. Thus, the equilibrium outcome is that neither partner offers to bear higher cost, and a birth takes place.

Now consider the case where (A26) to (A28) are satisfied, but we have:

$$
v_{f}<\left(\chi_{f, 0}+\frac{\alpha}{2}\right) \phi
$$

Subtracting both sides of this equation from (A26) gives:

$$
v_{m}>\left(1-\chi_{f, 0}+\frac{\alpha}{2}\right) \phi
$$

that is, (A26) and (A38) imply that (A37) holds with strict inequality. If neither partner offers to bear a higher than the default cost share, the couple will not have a baby because of (A38) (i.e., the woman will not agree). Also, the woman has no incentive to offer to bear higher cost share, because then she would want a baby even less, hence the outcome would be unchanged. Hence, to prove that in this situation a baby will be born as claimed in the proposition, we have to show that the man will offer to bear a sufficiently high cost for the woman to agree to having the baby. Hence, consider the decision of the man to bear a higher than the default cost share. Conditional on having the child, given (A34) the man's utility is strictly decreasing in his cost share. Hence, the only possibilities are that the man does not make an offer, in which case no birth takes place and the man gets utility (A32), or the man offers to bear just enough cost to make the woman indifferent between having the baby and not having the baby. The required cost share satisfies

$$
v_{f}=\left(\chi_{f}+\frac{\alpha}{2}\right) \phi
$$


and is therefore given by:

$$
\chi_{f}=\frac{v_{f}}{\phi}-\frac{\alpha}{2} .
$$

Given that (A27) holds, this is a feasible offer, i.e., $\chi_{f} \geq \chi_{f \text {,min }}$. We still need to show that offering this cost share and having the baby makes the man weakly better off compared to not making an offer. The man's utility with cost share $\chi_{f}$ and a baby being born is:

$$
\begin{aligned}
u_{m}\left(1, \chi_{f}\right) & =w_{m}-\left(1-\chi_{f}\right) \phi+\frac{\alpha}{2}\left[w_{f}+w_{m}-\phi\right]+v_{m} \\
& =w_{m}-\left(1-\frac{v_{f}}{\phi}+\frac{\alpha}{2}\right) \phi+\frac{\alpha}{2}\left[w_{f}+w_{m}-\phi\right]+v_{m} \\
& =w_{m}-(1+\alpha) \phi+\frac{\alpha}{2}\left[w_{f}+w_{m}\right]+v_{f}+v_{m} .
\end{aligned}
$$

We therefore have $u_{m}\left(1, \chi_{f}\right) \geq u_{m}\left(0, \chi_{f}\right)$ if the following condition is met:

$$
w_{m}-(1+\alpha) \phi+\frac{\alpha}{2}\left[w_{f}+w_{m}\right]+v_{f}+v_{m} \geq w_{m}+\frac{\alpha}{2}\left[w_{f}+w_{m}\right]
$$

or:

$$
v_{f}+v_{m} \geq(1+\alpha) \phi,
$$

which is (A26) and therefore satisfied. Hence, it is in the interest of the man to make the offer, and a birth will take place. The outcome for the remaining case where (A26) to (A28) are satisfied, but we have:

$$
v_{m}<\left(1-\chi_{f, 0}+\frac{\alpha}{2}\right) \phi
$$

(the man does not want the child given the default cost share) is parallel: the woman will offer to bear just enough cost for the birth to take place. Hence, (A26) to (A28) are also sufficient for a birth to take place, which completes the proof.

Regarding the last part of the proposition, if (A29) and (A30) are satisfied, (A27) and (A28) are never binding. Hence, (A26) is the only condition for a birth to take place, which is also the condition that characterizes fertility under commitment in Proposition 1.

Let us now consider, parallel to the analysis in Section B, how the distribution of the child care burden affects fertility under partial commitment. We consider an economy with a continuum of couples, with wages and cost shares identical across couples. Child preferences are heterogeneous in the population. We focus on the case of independent distributions $F_{f}\left(v_{f}\right)$ and $F_{m}\left(v_{m}\right)$ for female and male child preferences. Define $\tilde{v}_{f}$ and $\tilde{v}_{m}$ in the partial commitment case as:

$$
\begin{aligned}
\tilde{v}_{f} & =\left(\chi_{f, \min }+\frac{\alpha}{2}\right) \phi, \\
\tilde{v}_{m} & =\left(1-\chi_{f, \max }+\frac{\alpha}{2}\right) \phi .
\end{aligned}
$$


Given Proposition A6, the fertility rate for the economy will be given by:

$$
\begin{aligned}
E(b) & =\operatorname{Prob}\left(v_{f} \geq \tilde{v}_{f} \wedge v_{m} \geq \tilde{v}_{m} \wedge v_{f}+v_{m} \geq(1+\alpha) \phi\right) \\
& =\operatorname{Prob}\left(v_{f} \geq \tilde{v}_{f} \wedge v_{m} \geq \tilde{v}_{m}\right)-\operatorname{Prob}\left(v_{f} \geq \tilde{v}_{f} \wedge v_{m} \geq \tilde{v}_{m} \wedge v_{f}+v_{m}<(1+\alpha) \phi\right) .
\end{aligned}
$$

Writing this out in terms of the distribution functions gives:

$$
\begin{aligned}
E(b)=1-F_{f}\left(\tilde{v}_{f}\right)-F_{m}\left(\tilde{v}_{m}\right)+F_{f} & \left(\tilde{v}_{f}\right) F_{m}\left(\tilde{v}_{m}\right) \\
& -\int_{v_{m}=\tilde{v}_{m}}^{\infty} \max \left\{F_{f}\left((1+\alpha) \phi-v_{m}\right)-F_{f}\left(\tilde{v}_{f}\right), 0\right\} d F_{m}\left(v_{m}\right) .
\end{aligned}
$$

Here the first line is analogous to (A9) in the case without commitment, and the second line subtracts the probability that having a baby lowers the utility possibility frontier, i.e., (A26) is violated, even though both individual conditions (A27) and (A28) are satisfied.

We now would like to assess how a change in the distribution of the child care burden affects fertility under partial commitment. Consider the case where parents are able to move away from the default cost share $\chi_{f, 0}$ up to a maximum change of $\xi>0$, so that $\chi_{f, \min }=\chi_{f, 0}-\xi$, $\chi_{f, \min }=\chi_{f, 0}+\xi$. If the distribution functions are differentiable at $\tilde{v}_{f}$ and $\tilde{v}_{m}$, the marginal effect of a change in the default female cost share $\chi_{f, 0}$ on fertility in the case of partial commitment is:

$$
\begin{aligned}
\frac{\partial E(b)}{\partial \chi_{f}} & =\phi F_{m}^{\prime}\left(\tilde{v}_{m}\right)\left[1-F_{f}\left(\tilde{v}_{f}\right)\right]-\phi F_{f}^{\prime}\left(\tilde{v}_{f}\right)\left[1-F_{m}\left(\tilde{v}_{m}\right)\right] \\
& -\phi F_{m}^{\prime}\left(\tilde{v}_{m}\right)\left(F_{f}\left((1+\alpha) \phi-\tilde{v}_{m}\right)-F_{f}\left(\tilde{v}_{f}\right)\right)+\phi F_{f}^{\prime}\left(\tilde{v}_{f}\right)\left(F_{m}\left((1+\alpha) \phi-\tilde{v}_{f}\right)-F_{m}\left(\tilde{v}_{m}\right)\right) .
\end{aligned}
$$

or:

$$
\frac{\partial E(b)}{\partial \chi_{f}}=\phi F_{m}^{\prime}\left(\tilde{v}_{m}\right)\left[1-F_{f}\left((1+\alpha) \phi-\tilde{v}_{m}\right)\right]-\phi F_{f}^{\prime}\left(\tilde{v}_{f}\right)\left[1-F_{m}\left((1+\alpha) \phi-\tilde{v}_{f}\right)\right]
$$

The first (positive) term represents the increase in the number of men who agree to have a child if the default female cost share $\chi_{f}$ increases (and hence the male cost share declines), and the second (negative) term is the decline in agreement on the part of women. The first term has two components: $F_{m}^{\prime}\left(\tilde{v}_{m}\right)$ is the density of the distribution of male child preferences at the cutoff, which tells us how many men switch from disagreeing to agreeing with having a child as $\chi_{f}$ rises. The second component $1-F_{f}\left((1+\alpha) \phi-\tilde{v}_{m}\right)$ is the probability that the woman will also agree, conditional on the man being just at the cutoff. In the same way, the negative impact of a decline in female agreement on fertility, measured by $F_{f}^{\prime}\left(\tilde{v}_{f}\right)$, is weighted by the share of men agreeing to have a child conditional on the woman being at the cutoff, $1-F_{m}\left((1+\alpha) \phi-\tilde{v}_{f}\right)$.

Comparing the expression under partial commitment (A39) with the corresponding condition 
under no commitment (A10), we see that the impact of shifts in the burden of child care on fertility has the same form, except that under partial commitment the relevant agreement shares are conditional on the other partner being just at the indifference threshold. As long the gender that is more likely to be opposed to having a baby in general is also more likely to be opposed on the margin (which is not guaranteed for arbitrary distributions of child preferences, but is true under intuitive regularity conditions), the general intuition from the no commitment case (namely, that fertility can be raised by favoring the gender more likely to be opposed to a baby and with a more dense distribution of fertility preferences) carries over to the partial commitment case.

\section{E Data Description and Further Analysis}

The "Generations and Gender Programme" is a panel survey conducted in 19 countries (Wave 1), namely Australia, Austria, Belarus, Belgium, Bulgaria, Czech Republic, Estonia, France, Georgia, Germany, Hungary, Italy, Lithuania, Netherlands, Norway, Poland, Romania, Russian Federation, and Sweden. The survey can be connected to an associated survey conducted in Japan. As already mentioned above, we are interested in the answers to question a611 that asks

"Do you yourself want to have a/another baby now?"

and question a615 that asks

"Couples do not always have the same feelings about the number or timing of children. Does your partner/spouse want to have a/another baby now?"

For those respondents who didn't give an answer to question a611, we recover their intention towards having a baby from question a622, which asks the respondents about their plans to have a child within the next three years. ${ }^{2}$ We only use the answer to this question if the female household member is not currently pregnant.

\section{E.1 Sample Selection for Intention Data}

We select Wave 1 of our sample as follows. We use only those respondents who gave a clear answer to both questions $a 611^{3}$ and $a 615$, meaning that they responded either yes or no, and we also exclude couples who report that it is physically impossible for them to have a baby. In addition, we select couples in which the female partner is between the ages of 20 and 45 and the male partner between the ages of 20 and 55. These selection criteria naturally rule out

\footnotetext{
${ }^{2}$ This time span corresponds to the interval between two waves of the survey.

${ }^{3}$ Including those with recovered answers.
} 
single households. However, we do not restrict the sample to married couples, i.e. we include couples that are in any form of relationship. ${ }^{4}$ We also do not require partners to live in the same household. As we will see below, being married and living in the same household can impact our variables of interest. These selection criteria give us the sample sizes reported in Table A1.

Table A1: Wave 1 sample with questions about fertility preferences

\begin{tabular}{lrrr}
\hline \multirow{2}{*}{ Country } & \multicolumn{3}{c}{ No. of Respondents } \\
& female & male & Total \\
\hline Austria & 1,930 & 1,170 & 3,100 \\
Belgium & 1,060 & 956 & 2,016 \\
Bulgaria & 2,575 & 1,675 & 4,250 \\
Czech Republic & 1,163 & 1,086 & 2,249 \\
France & 1,505 & 1,185 & 2,690 \\
Germany & 1,445 & 1,151 & 2,596 \\
Lithuania & 990 & 1,143 & 2,133 \\
Norway & 2,231 & 2,175 & 4,406 \\
Poland & 2,212 & 1,654 & 3,866 \\
Romania & 1,474 & 1,791 & 3,265 \\
Russia & 1,530 & 1,378 & 2,908 \\
\hline Total & 18,115 & 15,364 & 33,479 \\
\hline
\end{tabular}

Table A2 reports additional descriptive statistics for the Wave 1 sample (see also Table 1). We define individual skill levels using the ISCED classification standard and assume that a person is high-skilled if her highest education level is of type 5 or 6 , meaning that she has completed some tertiary education. According to this definition, almost 30 percent of the female partners in the sample are high skilled, whereas for men it is only 26 percent. 67 percent of the female partners are working, where working is defined as either being officially employed, self-employed, or helping a family member in a family business or a farm. On the other hand, 87 percent of the male partners are working. 37 percent of couples in which the respondent has at least one biological child report to regularly use some institutional or paid child care arrangement. 42 percent regularly get help with child care from someone for whom caring for children is not a job. We interpret this as family based child care arrangements.

\footnotetext{
${ }^{4}$ There are no same sex couples in our sample.
} 
Table A2: Additional descriptive statistics of the sample (Wave 1)

\begin{tabular}{ll}
\hline & Mean \\
\hline Female partner high skilled (in \%) & 29.87 \\
Male partner high skilled (in \%) & 26.14 \\
Female partner working (in \%) & 67.01 \\
Male partner working (in \%) & 87.13 \\
Use institutional child care (in \%) & 37.23 \\
Use family child care (in \%) & 42.06 \\
\hline
\end{tabular}

Notes: 34,479 observations. Included countries are Austria, Belgium, Bulgaria, Czech Republic, France, Germany, Lithuania, Norway, Poland, Romania, and Russia. Child care questions only asked of couples with at least one child.

\section{E.2 Sample Selection for Birth Data}

When combining the first wave with data from Wave 2, we apply one additional selection criterion, namely that respondents are present in both waves. This selection gives us the sample size reported in Table A3. Note that the second wave is only available for a smaller number of countries. However, we find that the composition of the sample with respect to the variables reported in Table A2 is remarkably similar.

Table A3: Wave 2 sample with questions about fertility preferences and observed fertility

\begin{tabular}{lrrr}
\hline Country & \multicolumn{3}{c}{ No. of Respondents } \\
& female & male & Total \\
\hline Austria & 1,509 & 954 & 2,463 \\
Bulgaria & 1,821 & 1,163 & 2,984 \\
Czech Republic & 358 & 250 & 608 \\
France & 1,003 & 757 & 1,760 \\
Germany & 511 & 313 & 824 \\
Lithuania & 258 & 257 & 515 \\
Russia & 1,005 & 815 & 1,820 \\
\hline Total & 6,465 & 4,509 & 10,974 \\
\hline
\end{tabular}


When a respondent is present in both waves, we can compute whether they had (at least one) child in the time span between Waves 1 and $2 .{ }^{5}$ We do this using the difference in the number of biological children of the respondent, where biological children can be either with the current or a former partner. We therefore abstract from both adoption and fostering. We find that in roughly 15 percent of couples in our sample at least one child is born between Waves 1 and 2. We can also check how stable partnerships are in our sample. In fact, 89 percent of couples are still in a relationship with the same partner in Wave 2. Only 4 percent of respondents have changed the partner and about 7 percent have split up and live on their own.

To check how important child birth to single women is in the data, we construct a comparison group of female respondents who in Wave 1 report not to have a partner. For this group, we find that around 8 percent of respondents are having a child in between the two waves. This number may suggest that being in a partnership is not a prerequisite for having a baby. However, a further investigation of the partnership status of the respondents in Wave 2 reveals that the vast majority of children in this sample is born to women who have found a partner in the three years between the two waves. The number of children born to women who are single in both waves is very small.

\section{E.3 Determinants of Fertility Intentions}

Next, we provide some further investigation of the variables we are using to pin down parameters of our quantitative model. Specifically, we want to study what are covariates of fertility intentions, the degree of agreement, as well as the male share in child care activities in the sample. We therefore use our fertility intention data from Wave 1 and run a OLS regressions of intentions on regressors that may be related to our variables of interest. For all the regressions we use country fixed effects to account for different social and institutional environments. In Tables A4 and A5, we regress the female and the male fertility intention on all the variables reported in the descriptive statistics Tables 1 and A2, including a squared term for the age of the female partner and a variable for the age difference between the man and the woman. We use dummy variables for marriage, cohabitation, high skills (education), and so on. We run these regressions separately for couples with no children, one child, and two or more children. Note that we can only include dummies for the use of child care for couples that already have at least one child. In addition, we include a dummy variable for the gender of the first child. We also run two separate regressions with either marriage or cohabitation as a regressor, since the two tend to be highly collinear.

We find that the coefficients for both female and male fertility intentions are very similar in terms

\footnotetext{
${ }^{5}$ For 74.40 percent of our sample the time span was at most 40 months, and for 97.94 the time span was at most 50 months.
} 
Table A4: What covaries with women's intention to have a baby?

\begin{tabular}{|c|c|c|c|c|c|c|}
\hline & \multicolumn{2}{|c|}{ without children } & \multicolumn{2}{|c|}{ with 1 child } & \multicolumn{2}{|c|}{ with $2+$ children } \\
\hline & (1) & (2) & (1) & (2) & (1) & (2) \\
\hline Age woman & $\begin{array}{c}0.1528 \\
(0.0091)\end{array}$ & $\begin{array}{c}0.1490 \\
(0.0091)\end{array}$ & $\begin{array}{c}0.0744 \\
(0.0102)\end{array}$ & $\begin{array}{c}0.0768 \\
(0.0102)\end{array}$ & $\begin{array}{c}-0.0224 \\
(0.0070)\end{array}$ & $\begin{array}{r}-0.0247 \\
(0.0070)\end{array}$ \\
\hline Age squared/100 & $\begin{array}{c}-0.2508 \\
(0.0143)\end{array}$ & $\begin{array}{r}-0.2405 \\
(0.0143)\end{array}$ & $\begin{array}{r}-0.1476 \\
(0.0154)\end{array}$ & $\begin{array}{c}-0.1506 \\
(0.0154)\end{array}$ & $\begin{array}{c}0.0178 \\
(0.0096)\end{array}$ & $\begin{array}{c}0.0206 \\
(0.0096)\end{array}$ \\
\hline Age difference & $\begin{array}{c}0.0017 \\
(0.0016)\end{array}$ & $\begin{array}{c}0.0027 \\
(0.0016)\end{array}$ & $\begin{array}{r}-0.0060 \\
(0.0015)\end{array}$ & $\begin{array}{c}-0.0058 \\
(0.0015)\end{array}$ & $\begin{array}{c}-0.0002 \\
(0.0008)\end{array}$ & $\begin{array}{c}-0.0005 \\
(0.0008)\end{array}$ \\
\hline Married & $\begin{array}{c}0.2215 \\
(0.0157)\end{array}$ & & $\begin{array}{c}0.0709 \\
(0.0160)\end{array}$ & & $\begin{array}{c}-0.0377 \\
(0.0099)\end{array}$ & \\
\hline Cohabiting & & $\begin{array}{c}0.1483 \\
(0.0150)\end{array}$ & & $\begin{array}{c}0.0880 \\
(0.0446)\end{array}$ & & $\begin{array}{r}-0.0618 \\
(0.0319)\end{array}$ \\
\hline Educ. woman & $\begin{array}{c}-0.0191 \\
(0.0158)\end{array}$ & $\begin{array}{r}-0.0176 \\
(0.0160)\end{array}$ & $\begin{array}{c}0.0500 \\
(0.0155)\end{array}$ & $\begin{array}{c}0.0531 \\
(0.0154)\end{array}$ & $\begin{array}{c}0.0156 \\
(0.0076)\end{array}$ & $\begin{array}{c}0.0146 \\
(0.0076)\end{array}$ \\
\hline Educ. man & $\begin{array}{c}-0.0512 \\
(0.0149)\end{array}$ & $\begin{array}{r}-0.0499 \\
(0.0152)\end{array}$ & $\begin{array}{c}0.0637 \\
(0.0159)\end{array}$ & $\begin{array}{c}0.0677 \\
(0.0158)\end{array}$ & $\begin{array}{c}0.0241 \\
(0.0079)\end{array}$ & $\begin{array}{c}0.0229 \\
(0.0079)\end{array}$ \\
\hline Working woman & $\begin{array}{c}0.0545 \\
(0.0147)\end{array}$ & $\begin{array}{c}0.0488 \\
(0.0149)\end{array}$ & $\begin{array}{c}0.0113 \\
(0.0145)\end{array}$ & $\begin{array}{c}0.0130 \\
(0.0146)\end{array}$ & $\begin{array}{c}0.0043 \\
(0.0062)\end{array}$ & $\begin{array}{c}0.0034 \\
(0.0062)\end{array}$ \\
\hline Working man & $\begin{array}{c}0.0414 \\
(0.0172)\end{array}$ & $\begin{array}{c}0.0391 \\
(0.0175)\end{array}$ & $\begin{array}{c}-0.0002 \\
(0.0222)\end{array}$ & $\begin{array}{c}0.0020 \\
(0.0224)\end{array}$ & $\begin{array}{c}-0.0108 \\
(0.0092)\end{array}$ & $\begin{array}{r}-0.0143 \\
(0.0093)\end{array}$ \\
\hline Inst. child care & & & $\begin{array}{c}0.0540 \\
(0.0146)\end{array}$ & $\begin{array}{c}0.0534 \\
(0.0146)\end{array}$ & $\begin{array}{c}0.0147 \\
(0.0065)\end{array}$ & $\begin{array}{c}0.0148 \\
(0.0065)\end{array}$ \\
\hline Family child care & & & $\begin{array}{r}-0.0020 \\
(0.0133)\end{array}$ & $\begin{array}{c}-0.0034 \\
(0.0133)\end{array}$ & $\begin{array}{c}-0.0077 \\
(0.0064)\end{array}$ & $\begin{array}{r}-0.0069 \\
(0.0064)\end{array}$ \\
\hline First kid male & & & $\begin{array}{c}0.0156 \\
(0.0123)\end{array}$ & $\begin{array}{c}0.0157 \\
(0.0124)\end{array}$ & $\begin{array}{c}0.0052 \\
(0.0054)\end{array}$ & $\begin{array}{c}0.0054 \\
(0.0054)\end{array}$ \\
\hline Respondent female & $\begin{array}{c}-0.0126 \\
(0.0128)\end{array}$ & $\begin{array}{c}-0.0172 \\
(0.0129)\end{array}$ & $\begin{array}{c}0.0204 \\
(0.0126)\end{array}$ & $\begin{array}{c}0.0198 \\
(0.0127)\end{array}$ & $\begin{array}{c}-0.0323 \\
(0.0056)\end{array}$ & $\begin{array}{r}-0.0326 \\
(0.0056)\end{array}$ \\
\hline Number of Cases & 5744 & 5760 & 6239 & 6245 & 12358 & 12378 \\
\hline R-Square & 0.557 & 0.548 & 0.461 & 0.461 & 0.140 & 0.138 \\
\hline
\end{tabular}

Robust standard errors in parentheses. 
Table A5: What covaries with men's intention to have a baby?

\begin{tabular}{|c|c|c|c|c|c|c|}
\hline & \multicolumn{2}{|c|}{ without children } & \multicolumn{2}{|c|}{ with 1 child } & \multicolumn{2}{|c|}{ with $2+$ children } \\
\hline & (1) & (2) & (1) & (2) & (1) & (2) \\
\hline Age woman & $\begin{array}{c}0.1355 \\
(0.0093)\end{array}$ & $\begin{array}{c}0.1320 \\
(0.0094)\end{array}$ & $\begin{array}{c}0.0472 \\
(0.0107)\end{array}$ & $\begin{array}{c}0.0502 \\
(0.0106)\end{array}$ & $\begin{array}{r}-0.0169 \\
(0.0073)\end{array}$ & $\begin{array}{r}-0.0192 \\
(0.0073)\end{array}$ \\
\hline Age squared/100 & $\begin{array}{c}-0.2270 \\
(0.0146)\end{array}$ & $\begin{array}{c}-0.2171 \\
(0.0147)\end{array}$ & $\begin{array}{r}-0.1067 \\
(0.0161)\end{array}$ & $\begin{array}{c}-0.1104 \\
(0.0161)\end{array}$ & $\begin{array}{c}0.0086 \\
(0.0101)\end{array}$ & $\begin{array}{c}0.0115 \\
(0.0101)\end{array}$ \\
\hline Age difference & $\begin{array}{c}0.0004 \\
(0.0016)\end{array}$ & $\begin{array}{c}0.0013 \\
(0.0017)\end{array}$ & $\begin{array}{c}-0.0061 \\
(0.0016)\end{array}$ & $\begin{array}{c}-0.0059 \\
(0.0016)\end{array}$ & $\begin{array}{c}-0.0025 \\
(0.0008)\end{array}$ & $\begin{array}{r}-0.0028 \\
(0.0008)\end{array}$ \\
\hline Married & $\begin{array}{c}0.2250 \\
(0.0157)\end{array}$ & & $\begin{array}{c}0.0846 \\
(0.0162)\end{array}$ & & $\begin{array}{c}-0.0367 \\
(0.0105)\end{array}$ & \\
\hline Cohabiting & & $\begin{array}{c}0.1494 \\
(0.0155)\end{array}$ & & $\begin{array}{c}0.1025 \\
(0.0420)\end{array}$ & & $\begin{array}{r}-0.0937 \\
(0.0393)\end{array}$ \\
\hline Educ. woman & $\begin{array}{c}-0.0199 \\
(0.0161)\end{array}$ & $\begin{array}{r}-0.0178 \\
(0.0163)\end{array}$ & $\begin{array}{c}0.0414 \\
(0.0161)\end{array}$ & $\begin{array}{c}0.0448 \\
(0.0161)\end{array}$ & $\begin{array}{c}0.0060 \\
(0.0080)\end{array}$ & $\begin{array}{c}0.0046 \\
(0.0080)\end{array}$ \\
\hline Educ. man & $\begin{array}{c}-0.0306 \\
(0.0152)\end{array}$ & $\begin{array}{c}-0.0287 \\
(0.0154)\end{array}$ & $\begin{array}{c}0.0731 \\
(0.0162)\end{array}$ & $\begin{array}{c}0.0774 \\
(0.0162)\end{array}$ & $\begin{array}{c}0.0324 \\
(0.0083)\end{array}$ & $\begin{array}{c}0.0313 \\
(0.0083)\end{array}$ \\
\hline Working woman & $\begin{array}{c}0.0495 \\
(0.0151)\end{array}$ & $\begin{array}{c}0.0444 \\
(0.0153)\end{array}$ & $\begin{array}{c}0.0223 \\
(0.0147)\end{array}$ & $\begin{array}{c}0.0244 \\
(0.0147)\end{array}$ & $\begin{array}{c}0.0015 \\
(0.0067)\end{array}$ & $\begin{array}{c}0.0006 \\
(0.0067)\end{array}$ \\
\hline Working man & $\begin{array}{c}0.0779 \\
(0.0173)\end{array}$ & $\begin{array}{c}0.0759 \\
(0.0175)\end{array}$ & $\begin{array}{c}0.0107 \\
(0.0227)\end{array}$ & $\begin{array}{c}0.0135 \\
(0.0228)\end{array}$ & $\begin{array}{c}-0.0241 \\
(0.0106)\end{array}$ & $\begin{array}{r}-0.0274 \\
(0.0106)\end{array}$ \\
\hline Inst. child care & & & $\begin{array}{c}0.0668 \\
(0.0148)\end{array}$ & $\begin{array}{c}0.0656 \\
(0.0148)\end{array}$ & $\begin{array}{c}-0.0051 \\
(0.0068)\end{array}$ & $\begin{array}{r}-0.0047 \\
(0.0068)\end{array}$ \\
\hline Family child care & & & $\begin{array}{c}0.0092 \\
(0.0135)\end{array}$ & $\begin{array}{c}0.0069 \\
(0.0136)\end{array}$ & $\begin{array}{c}-0.0018 \\
(0.0068)\end{array}$ & $\begin{array}{r}-0.0015 \\
(0.0068)\end{array}$ \\
\hline First kid male & & & $\begin{array}{c}0.0068 \\
(0.0126)\end{array}$ & $\begin{array}{c}0.0066 \\
(0.0126)\end{array}$ & $\begin{array}{c}-0.0124 \\
(0.0058)\end{array}$ & $\begin{array}{c}-0.0121 \\
(0.0058)\end{array}$ \\
\hline Respondent female & $\begin{array}{c}0.0644 \\
(0.0131)\end{array}$ & $\begin{array}{c}0.0604 \\
(0.0132)\end{array}$ & $\begin{array}{c}0.0383 \\
(0.0130)\end{array}$ & $\begin{array}{c}0.0373 \\
(0.0130)\end{array}$ & $\begin{array}{c}0.0249 \\
(0.0059)\end{array}$ & $\begin{array}{c}0.0245 \\
(0.0059)\end{array}$ \\
\hline Number of Cases & 5744 & 5760 & 6239 & 6245 & 12358 & 12378 \\
\hline R-Square & 0.555 & 0.547 & 0.483 & 0.481 & 0.152 & 0.151 \\
\hline
\end{tabular}

Robust standard errors in parentheses. 
of signs, magnitude, and significance. The results show a clear hump-shaped pattern of fertility intentions by age for both men and women. Figure A1 visualizes this pattern for couples without children and those with one child, where we evaluate all other variables at their sample means. We find that men would agree on having a child a little earlier than women. The age difference between partners, although statistically significant, plays a quantitatively small role.

Figure A1: Life cycle profiles of fertility intentions and agreement
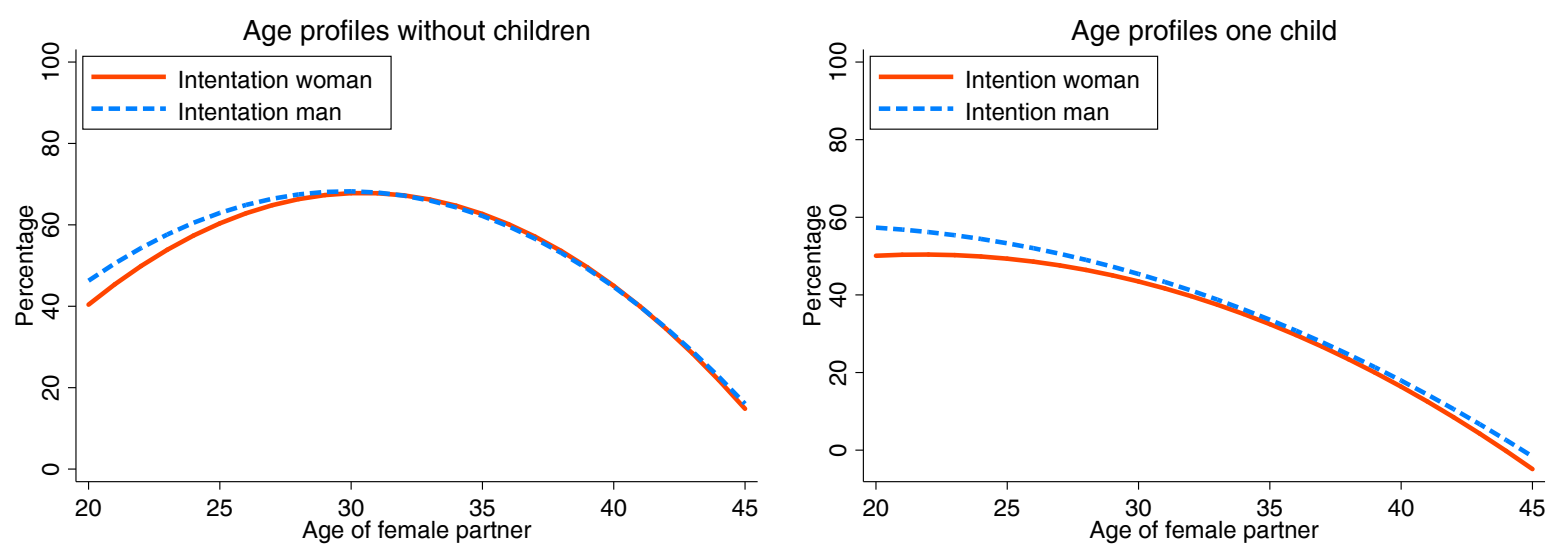

The security of living in a marriage or cohabitation with a partner are major determinants for wanting children at all. For couples without children, the coefficients of the respective dummies are positive, large, and highly significant. For second or higher-order children the effects are much less pronounced, and even turn negative for couples with two or more children. Tertiary education (especially that of men) seems to have adverse effects fertility intentions. This suggests that there is a lot of dispersion in the desire for children of the highly educated workforce. While there are more couples with high skills who want no children at all, those who do get children want more of them than their less educated counterparts. Finally, having a job and therefore a secure source of income is an important covariate for the decision whether to have children at all. The coefficients are positive and significant for employment of both partners on fertility intentions of both men and women. For couples that already have one child, the use (and therefore the availability) of institutional or paid child care comes with a larger intention to have another child. The use of family child care arrangements, on the other hand, hardly covaries with fertility intentions. A reason for this may be that institutional child care usually takes care of children throughout the day so that parents can go to work. Help with child care from the family can also include bringing the children to the grandparents one day on the weekend. The gender of the first child has hardly any impact on fertility intentions. If anything, women's intention to have a second child are slightly larger when the first child is a boy. Finally, the gender of the respondent 
plays almost no role in the reported fertility intention of women. In contrast, women tend to slightly overestimate the desire for fertility of their male partners.

\section{E.4 Determinants of Agreement}

In Table A6 we regress our dummy for agreement of the partners (AGREE) on the same covariates as in the previous tables. We find a hump shaped pattern of agreement with regards to the age of the woman. This suggests that at least part of the conflict between men and women on whether to have a baby is due to differences in desired timing. Marriage and cohabitation come along with a significantly higher level of agreement, where cohabitation tends to play a larger role at least for the second child. This observation suggests, as emphasized by our theoretical analysis, that the ability to commit is a major determinant of agreement and disagreement. With respect to education and having a job, we find similar patterns as in the previous two regressions. Again, for both men and women having a job comes along with a significantly higher degree of agreement on having children at all. Interestingly, the use or availability of institutional child care doesn't impact agreement much, while the use of family child care comes along with a significantly lower level of agreement. Finally, there is a discrepancy between reported agreement between men and women who already have two or more children.

\section{E.5 Determinants of Men's Participation in Child Care}

In Table A7 we study covariates of the man's share in caring for the child/children. We exclude age variables from this table, as none of our age covariates turned out significant. Being married is not a strong predictor of men's share in child care, but cohabitation is. When partners have a child and live in one household, not surprisingly, the male partner will take a larger share in child rearing. Men who are educated or whose partners are educated tend to spend more time

with the children. Regarding employment, we find that when the mother works, the father has to take a larger share in caring for the children, and vice versa. The use of institutional child care also leads the father to look after the children more. This is consistent with the interpretation underlying our policy analysis, namely that institutional child care tends to substitute child care that is (usually) provided by the mother. Last but not least, men tend to overestimate (or women underestimate) how much time they spend on child rearing.

\section{E.6 Computing Men's Share in Caring for Children with Time Use Data}

In our analysis, we measure the distribution of the burden of child care within the household using a number of questions in the GGP data set on which parent usually performs a number of specific child care activities. A limitation of this data is that it is qualitative and does not allow us to pin down exactly how much time mothers versus fathers spend on child care. To address 
Table A6: What covaries with agreement on wanting a baby?

\begin{tabular}{|c|c|c|c|c|c|c|}
\hline & \multicolumn{2}{|c|}{ without children } & \multicolumn{2}{|c|}{ with 1 child } & \multicolumn{2}{|c|}{ with $2+$ children } \\
\hline & (1) & (2) & (1) & (2) & (1) & (2) \\
\hline Age woman & $\begin{array}{c}0.0976 \\
(0.0160)\end{array}$ & $\begin{array}{c}0.0880 \\
(0.0162)\end{array}$ & $\begin{array}{c}0.0719 \\
(0.0197)\end{array}$ & $\begin{array}{c}0.0777 \\
(0.0194)\end{array}$ & $\begin{array}{c}0.0184 \\
(0.0266)\end{array}$ & $\begin{array}{c}0.0184 \\
(0.0265)\end{array}$ \\
\hline Age squared/100 & $\begin{array}{c}-0.1496 \\
(0.0260)\end{array}$ & $\begin{array}{r}-0.1321 \\
(0.0263)\end{array}$ & $\begin{array}{c}-0.1401 \\
(0.0316)\end{array}$ & $\begin{array}{c}-0.1484 \\
(0.0312)\end{array}$ & $\begin{array}{r}-0.0572 \\
(0.0392)\end{array}$ & $\begin{array}{c}-0.0573 \\
(0.0391)\end{array}$ \\
\hline Age difference & $\begin{array}{c}-0.0001 \\
(0.0022)\end{array}$ & $\begin{array}{c}0.0006 \\
(0.0023)\end{array}$ & $\begin{array}{r}-0.0049 \\
(0.0025)\end{array}$ & $\begin{array}{c}-0.0047 \\
(0.0025)\end{array}$ & $\begin{array}{c}0.0029 \\
(0.0031)\end{array}$ & $\begin{array}{c}0.0027 \\
(0.0031)\end{array}$ \\
\hline Married & $\begin{array}{c}0.1993 \\
(0.0192)\end{array}$ & & $\begin{array}{c}0.1242 \\
(0.0238)\end{array}$ & & $\begin{array}{c}-0.0182 \\
(0.0341)\end{array}$ & \\
\hline Cohabiting & & $\begin{array}{c}0.2191 \\
(0.0249)\end{array}$ & & $\begin{array}{c}0.3551 \\
(0.0620)\end{array}$ & & $\begin{array}{r}-0.1232 \\
(0.0855)\end{array}$ \\
\hline Educ. woman & $\begin{array}{c}-0.0370 \\
(0.0218)\end{array}$ & $\begin{array}{r}-0.0300 \\
(0.0217)\end{array}$ & $\begin{array}{c}0.0282 \\
(0.0225)\end{array}$ & $\begin{array}{c}0.0293 \\
(0.0224)\end{array}$ & $\begin{array}{c}0.0265 \\
(0.0321)\end{array}$ & $\begin{array}{c}0.0236 \\
(0.0319)\end{array}$ \\
\hline Educ. man & $\begin{array}{c}-0.0287 \\
(0.0214)\end{array}$ & $\begin{array}{c}-0.0219 \\
(0.0214)\end{array}$ & $\begin{array}{c}0.0480 \\
(0.0221)\end{array}$ & $\begin{array}{c}0.0531 \\
(0.0218)\end{array}$ & $\begin{array}{c}0.0722 \\
(0.0315)\end{array}$ & $\begin{array}{c}0.0721 \\
(0.0314)\end{array}$ \\
\hline Working woman & $\begin{array}{c}0.0825 \\
(0.0226)\end{array}$ & $\begin{array}{c}0.0690 \\
(0.0228)\end{array}$ & $\begin{array}{c}0.0197 \\
(0.0215)\end{array}$ & $\begin{array}{c}0.0233 \\
(0.0214)\end{array}$ & $\begin{array}{c}0.0090 \\
(0.0282)\end{array}$ & $\begin{array}{c}0.0060 \\
(0.0282)\end{array}$ \\
\hline Working man & $\begin{array}{c}0.0895 \\
(0.0291)\end{array}$ & $\begin{array}{c}0.0740 \\
(0.0292)\end{array}$ & $\begin{array}{c}-0.0078 \\
(0.0314)\end{array}$ & $\begin{array}{c}-0.0057 \\
(0.0317)\end{array}$ & $\begin{array}{c}0.0220 \\
(0.0418)\end{array}$ & $\begin{array}{c}0.0179 \\
(0.0416)\end{array}$ \\
\hline Inst. child care & & & $\begin{array}{c}0.0046 \\
(0.0202)\end{array}$ & $\begin{array}{c}0.0087 \\
(0.0201)\end{array}$ & $\begin{array}{c}-0.0099 \\
(0.0279)\end{array}$ & $\begin{array}{c}-0.0095 \\
(0.0278)\end{array}$ \\
\hline Family child care & & & $\begin{array}{r}-0.0469 \\
(0.0188)\end{array}$ & $\begin{array}{r}-0.0525 \\
(0.0188)\end{array}$ & $\begin{array}{c}-0.0770 \\
(0.0278)\end{array}$ & $\begin{array}{r}-0.0766 \\
(0.0277)\end{array}$ \\
\hline First kid male & & & $\begin{array}{c}-0.0099 \\
(0.0178)\end{array}$ & $\begin{array}{c}-0.0107 \\
(0.0178)\end{array}$ & $\begin{array}{c}-0.0272 \\
(0.0255)\end{array}$ & $\begin{array}{r}-0.0250 \\
(0.0255)\end{array}$ \\
\hline Respondent female & $\begin{array}{c}0.0238 \\
(0.0185)\end{array}$ & $\begin{array}{c}0.0179 \\
(0.0184)\end{array}$ & $\begin{array}{c}0.0137 \\
(0.0186)\end{array}$ & $\begin{array}{c}0.0160 \\
(0.0185)\end{array}$ & $\begin{array}{c}-0.0596 \\
(0.0257)\end{array}$ & $\begin{array}{r}-0.0636 \\
(0.0258)\end{array}$ \\
\hline Number of Cases & 2948 & 2963 & 2887 & 2892 & 1575 & 1579 \\
\hline R-Square & 0.742 & 0.742 & 0.721 & 0.721 & 0.408 & 0.409 \\
\hline
\end{tabular}

Robust standard errors in parentheses. 
Table A7: What covaries with male participation in child care?

\begin{tabular}{|c|c|c|c|c|}
\hline & \multicolumn{2}{|c|}{ with 1 child } & \multicolumn{2}{|c|}{ with $2+$ children } \\
\hline & (1) & (2) & (1) & (2) \\
\hline \multirow[t]{2}{*}{ Married } & 0.0113 & & 0.0067 & \\
\hline & $(0.0058)$ & & $(0.0046)$ & \\
\hline \multirow[t]{2}{*}{ Cohabiting } & & 0.1506 & & 0.1618 \\
\hline & & $(0.0202)$ & & $(0.0207)$ \\
\hline \multirow[t]{2}{*}{ Educ. woman } & 0.0172 & 0.0165 & 0.0178 & 0.0177 \\
\hline & $(0.0055)$ & $(0.0054)$ & $(0.0040)$ & $(0.0040)$ \\
\hline \multirow[t]{2}{*}{ Educ. man } & 0.0180 & 0.0191 & 0.0197 & 0.0198 \\
\hline & $(0.0054)$ & $(0.0053)$ & $(0.0039)$ & $(0.0039)$ \\
\hline \multirow[t]{2}{*}{ Working woman } & 0.0833 & 0.0850 & 0.0786 & 0.0794 \\
\hline & $(0.0051)$ & $(0.0051)$ & $(0.0034)$ & $(0.0034)$ \\
\hline \multirow[t]{2}{*}{ Working man } & -0.0714 & -0.0722 & -0.0669 & -0.0667 \\
\hline & $(0.0091)$ & $(0.0091)$ & $(0.0062)$ & $(0.0062)$ \\
\hline \multirow[t]{2}{*}{ Inst. child care } & 0.0204 & 0.0209 & 0.0127 & 0.0125 \\
\hline & $(0.0050)$ & $(0.0049)$ & $(0.0033)$ & $(0.0033)$ \\
\hline \multirow[t]{2}{*}{ Family child care } & 0.0079 & 0.0081 & 0.0021 & 0.0027 \\
\hline & $(0.0046)$ & $(0.0045)$ & $(0.0033)$ & $(0.0033)$ \\
\hline \multirow[t]{2}{*}{ First kid male } & 0.0023 & 0.0028 & -0.0004 & -0.0002 \\
\hline & $(0.0043)$ & $(0.0042)$ & $(0.0030)$ & $(0.0030)$ \\
\hline \multirow[t]{2}{*}{ Respondent female } & -0.0738 & -0.0698 & -0.0670 & -0.0655 \\
\hline & $(0.0044)$ & $(0.0045)$ & $(0.0030)$ & $(0.0030)$ \\
\hline Number of Cases & 6172 & 6178 & 12208 & 12228 \\
\hline R-Square & 0.790 & 0.793 & 0.805 & 0.806 \\
\hline
\end{tabular}

Robust standard errors in parentheses. 
this limitation, here we compare our results on the distribution of the burden of child care to a similar computation based on international time use data.

Figure A2: Disagreement over fertility and men's share in caring for children, measured with time use data

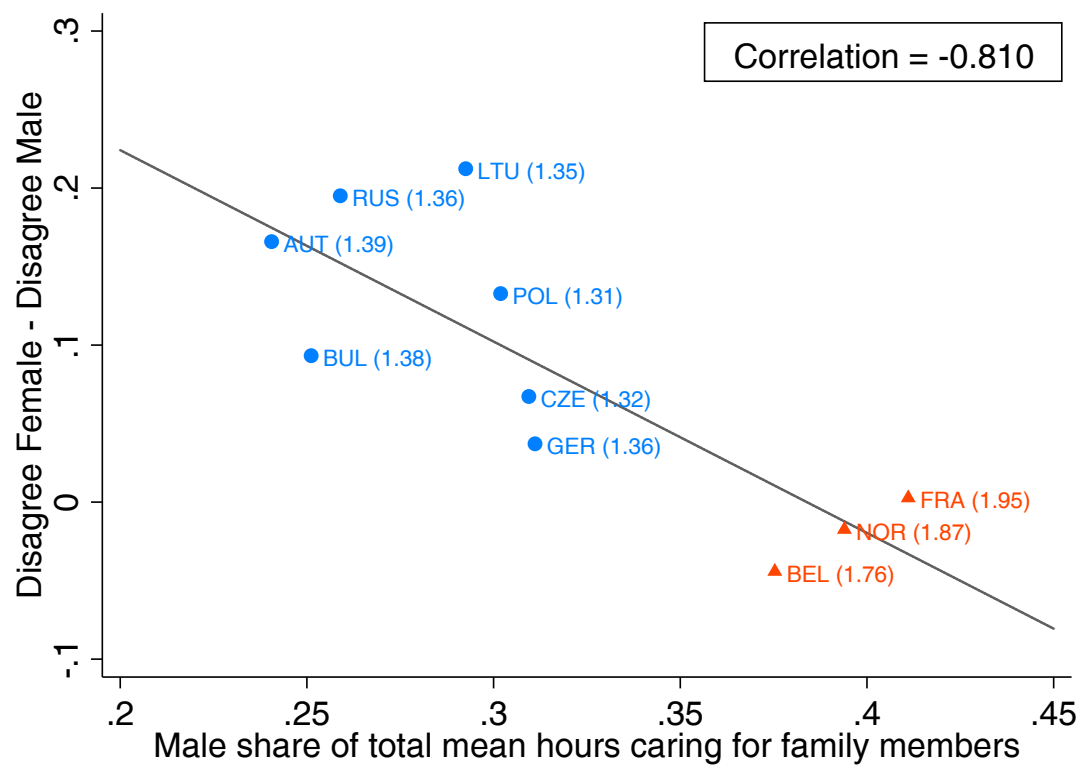

Notes: Time use data from International Social Survey Program. The data set used is "Family and Changing Gender Roles IV 2012." Distribution of child care computed based on self-reported child care by women and men in households with both partners present at least one child under the age of 5 .

We use time use data from the most recent available Family and Changing Roles (2012) module of the International Social Survey Programme (ISSP). ${ }^{6}$ The ISSP provides representative survey data from almost 50 member countries, including ten of the eleven countries in our GGP sample (no data is available for Russia). The Family and Changing Roles module contains detailed information on attitudes towards gender roles within the family, and, importantly, time use information for the respondent and their partner. The ISSP interviews one adult in each household. Each respondent reports for how many hours she or he spends looking after family members and how many hours the partners spends. We utilize this measure as a proxy for child care time. We restrict the sample to individuals living with a partner and at least one child up to the age of 5 . We compute the female and male share in child care using only self-reported time use (i.e., we do not use the report for the partner's time use), although using both reports yields similar

\footnotetext{
${ }^{6}$ Citation: ISSP Research Group (2016): International Social Survey Programme: Family and Changing Gender Roles IV - ISSP 2012. GESIS Data Archive, Cologne. ZA5900 Data file Version 4.0.0, doi: $10.4232 / 1.12661$
} 
patterns.

Figure A2 uses this data to display a version of Figure 2 based on the time use data instead of the GGP data. We see that despite the different data source, the basic pattern is essentially the same. The level and distribution of the implied male share of time cost is very similar in the GGP data and in the time use data, and the male contribution to child care contributes to be highly correlated with disagreement between women and men about fertility. The result suggest that our measure of the distribution of the burden of child care provides a good approximation to measures based on time use. 